\title{
TU/e EN⿴HONE

\section{Field and temperature dependence of the photocurrent in polymer/fullerene bulk heterojunction solar cells}

\section{Citation for published version (APA):}

Gommans, H. H. P., Kemerink, M., Kramer, J. M., \& Janssen, R. A. J. (2005). Field and temperature dependence of the photocurrent in polymer/fullerene bulk heterojunction solar cells. Applied Physics Letters, 87(12), 122104-1/3. [122104]. https://doi.org/10.1063/1.2056609

DOI:

10.1063/1.2056609

Document status and date:

Published: 01/01/2005

\section{Document Version:}

Publisher's PDF, also known as Version of Record (includes final page, issue and volume numbers)

\section{Please check the document version of this publication:}

- A submitted manuscript is the version of the article upon submission and before peer-review. There can be important differences between the submitted version and the official published version of record. People interested in the research are advised to contact the author for the final version of the publication, or visit the $\mathrm{DOI}$ to the publisher's website.

- The final author version and the galley proof are versions of the publication after peer review.

- The final published version features the final layout of the paper including the volume, issue and page numbers.

Link to publication

\section{General rights}

Copyright and moral rights for the publications made accessible in the public portal are retained by the authors and/or other copyright owners and it is a condition of accessing publications that users recognise and abide by the legal requirements associated with these rights.

- Users may download and print one copy of any publication from the public portal for the purpose of private study or research.

- You may not further distribute the material or use it for any profit-making activity or commercial gain

- You may freely distribute the URL identifying the publication in the public portal.

If the publication is distributed under the terms of Article 25fa of the Dutch Copyright Act, indicated by the "Taverne" license above, please follow below link for the End User Agreement:

www.tue.nl/taverne

Take down policy

If you believe that this document breaches copyright please contact us at:

openaccess@tue.nl

providing details and we will investigate your claim. 


\title{
Field and temperature dependence of the photocurrent in polymer/fullerene bulk heterojunction solar cells
}

\author{
H. H. P. Gommans, M. Kemerink, ${ }^{\text {a) }}$ J. M. Kramer, and R. A. J. Janssen \\ Department of Applied Physics, Eindhoven University of Technology, 5600 MB Eindhoven, The Netherlands
}

(Received 7 July 2005; accepted 5 August 2005; published online 14 September 2005)

\begin{abstract}
The photocurrent in polymer/fullerene blends is characterized as a function of bias at temperatures ranging from 125 to $300 \mathrm{~K}$. Assuming a constant generation rate and bimolecular recombination, the results are numerically modeled within the drift-diffusion approximation. Bimolecular recombination is found to be a dominant factor in the field dependence of the photocurrent in the entire measured voltage range. Inclusion of field dependent geminate pair dissociation and recombination via the Onsager expressions gives a much stronger field dependence than experimentally observed. From the temperature dependence of the extracted mobilities, we can simultaneously estimate the broadening of the transporting highest occupied and lowest unoccupied molecular orbital levels. (C) 2005 American Institute of Physics. [DOI: 10.1063/1.2056609]
\end{abstract}

Blends of conjugated polymer and fullerene derivatives are considered promising candidates for thin-film organic solar cells. ${ }^{1}$ The photovoltaic response is based on an-ultrafast electron transfer from the conjugated polymer excited state to the buckminsterfullerene, with a quantum efficiency close to unity. ${ }^{2}$ Combined with the large interface area for charge separation due to the intimate blending ${ }^{3}$ and the efficient carrier transport across the thin film, power conversion efficiencies up to $3 \%$ have been reported. ${ }^{3-5}$

In order to improve the efficiency of the solar cell, fundamental aspects of the device operation have to be examined. Some progress has already been made: The temperature dependence of the photocurrent under short-circuit conditions, $J_{\mathrm{SC}}$, is suggested to result from the temperature dependence in the charge transport in combination with recombination with shallow traps ${ }^{6}$ and space-charge effects. ${ }^{7}$ Recently, geminate recombination of generated bound electron-hole pairs, based on Onsager's theory, was used to explain the field and temperature dependence. ${ }^{8}$ Here, these effects will be related to gradients in the electron and hole quasi Fermi levels that ultimately induce the photovoltaic effect. This makes it possible to recognize the importance of their contributions to the photocurrent.

In this letter, we will model the photocurrent in polymer: fullerene bulk heterojunction solar cells as a function of bias for different temperatures by drift-diffusion equations. This allows us to examine how dissimilar mobilities, as well as a metastable charge transfer (CT) state, affect the field and temperature dependence of the photocurrent. A similar approach was recently used in the modeling of bilayer polyfluorene-based photovoltaic devices ${ }^{9}$ and polymer: fullerene cells. ${ }^{10}$ The set of coupled partial differential equations is given by

$$
\begin{aligned}
& \bar{\nabla} \cdot(\varepsilon \bar{\nabla} \phi)=q(n-p), \\
& \bar{\nabla} \cdot \bar{J}_{n}=-q\left(-\partial_{t} n-R+G\right), \\
& \bar{\nabla} \cdot \bar{J}_{p}=q\left(-\partial_{t} p-R+G\right),
\end{aligned}
$$

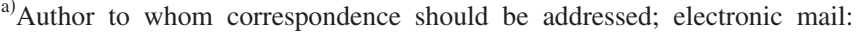
m.kemerink@tue.nl
}

$$
\begin{aligned}
& \bar{J}_{n}=q\left(D_{n} \bar{\nabla} n-\mu_{n} n \bar{\nabla} \phi\right), \\
& \bar{J}_{p}=q\left(-D_{p} \bar{\nabla} p-\mu_{p} p \bar{\nabla} \phi\right),
\end{aligned}
$$

where $\phi$ denotes the electric potential, $n$ and $p$ are the free carrier concentrations of electrons and holes, and $J_{n}$ and $J_{p}$ are the electron and hole current density, respectively. $D_{n}$, $D_{p}, \mu_{n}$, and $\mu_{p}$ are the diffusion coefficients and the mobilities of electrons and holes, respectively. $R$ is the recombination rate, $G$ is the generation rate, and $\varepsilon=\varepsilon_{r} \varepsilon_{0}$ with $\varepsilon_{0}$ as the permittivity of vacuum and $\varepsilon_{r}$ as the relative permittivity that is assumed constant. The Einstein relation for diffusion, $D_{n / p}=k_{B} T / q \mu_{n / p}$, is assumed to hold, where $k_{B}$ is the Boltzmann constant, $T$ is the temperature, and $q$ is the elementary charge.

The simulations described in this letter have been performed using the software package CURRY, developed within Philips Research. ${ }^{11}$ The mobilities are assumed to be a function of temperature only. Given the bias range, this restriction is not severely limiting (at $2 \mathrm{~V}$ typically a factor of 2 increase results) and merely allows us to reduce the number of free variables.

Prior to sample preparation, the indium tin oxidecovered glass substrates were first cleaned by ultrasonic treatment in acetone, rubbing with soap, rinsing with demineralized water, refluxing with isopropanol, and finally $20 \mathrm{~min}$ of ultraviolet-ozone treatment. Subsequently, a $100 \mathrm{~nm}$ thick layer of polyethylenedioxythiophene: polystyrenesulfonate (PEDOT:PSS) was spin coated (1500 rpm;90 s) from an aqueous dispersion under ambient conditions on the cleaned substrates and dried by annealing for $1 \mathrm{~min}$ at $180^{\circ} \mathrm{C}$. Then, a $90 \mathrm{~nm}$ thick layer was spin coated (1000 rpm;90 s) on top of the PEDOT:PSS from a chlorobenzene solution consisting of poly[2-methoxy-5(3', 7'-dimethyloctyloxy)-1,4-phenylene vinylene] (MDMOPPV) and 1-(3-methoxycarbonyl)propyl-1-phenyl-[6,6]methanofullerene (PCBM) in the mixing ratio 1:4 (by weight), which was stirred vigorously overnight in the dark. The substrates were then transferred into a glovebox filled with nitrogen atmosphere $\left(\left[\mathrm{O}_{2}\right]<1 \mathrm{ppm}\right.$ and $\left[\mathrm{H}_{2} \mathrm{O}\right]$ $<1 \mathrm{ppm}$ ). From there, they were introduced in a vacuum deposition chamber $\left(p \sim 10^{-6}\right.$ mbar $)$. $1.0 \mathrm{~nm}$ of $\mathrm{LiF}$ and 


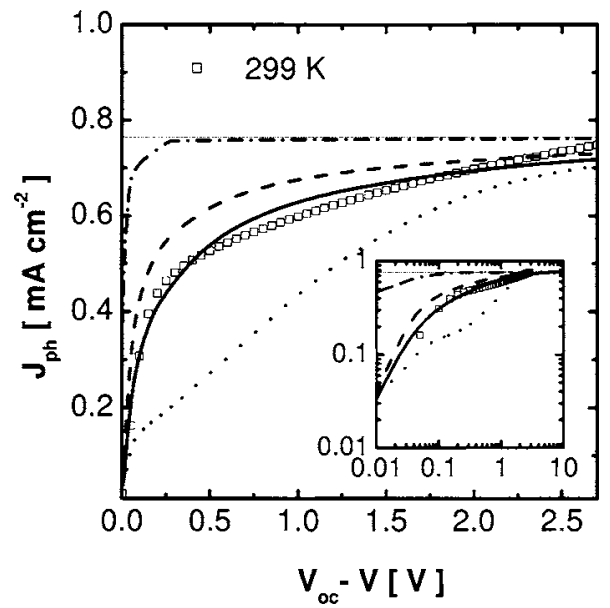

FIG. 1. The photocurrent vs bias obtained at $299 \mathrm{~K}$ (squares). The curves give the numerical solution of the drift-diffusion equation after optimizing $G_{0}$ (dashed), $G_{0}, \mu_{e}$, and $\mu_{h}$ (solid), including the presence of a CT state $\left(k_{f} / k_{0}=15\right.$, dotted) and in the absence of recombination (dashed-dotted). The thin line indicates the maximum output $J_{\mathrm{ph}}=e G_{0} l$. The inset shows the same data on a double-log scale.

$100 \mathrm{~nm}$ of $\mathrm{Al}$ were deposited right after each other, while the sample temperature was kept below $40{ }^{\circ} \mathrm{C}$. Inside the glovebox, the samples were mounted in a variable temperature continuous flow cryostat, which was subsequently evacuated. The current-voltage characterization was performed using a Keithley 2410 source meter, using a white halogen lamp for illumination.

In Fig. 1, the photocurrent $\left(J_{\mathrm{ph}}\right)$ and open-circuit potential $\left(V_{\text {oc }}\right)$ at $299 \mathrm{~K}$ are determined by subtracting the current obtained in the dark from that under illumination. In the absence of gap states, the recombination is given by the bimolecular recombination rate, which we assume to be described by the Langevin equation $R=\gamma n p$, with $\gamma=e\left(\mu_{n}\right.$ $\left.+\mu_{p}\right) /\left(\varepsilon_{0} \varepsilon_{r}\right) .{ }^{12,13}$ The generation rate, $G=G_{0}$, is assumed uniform. The dashed curve is obtained for mobilities that were taken from literature $\left(\mu_{n}=2.0 \times 10^{-3}\right.$ and $\mu_{p}=1.4$ $\left.\times 10^{-4} \mathrm{~cm}^{2} / \mathrm{V} \mathrm{s}\right){ }^{8}$ Here, the only free parameter was $G_{0}$ which determines the saturation value for the photocurrent. The thin line in Fig. 1 indicates the theoretical maximum device output, $e G_{0} \ell$, with $\ell$ the layer thickness. The solid line is obtained by including the mobilities in the optimization procedure, which yielded somewhat different values for $\mu_{n}\left(2 \times 10^{-2}\right)$ and $\mu_{p}\left(2 \times 10^{-5}\right)$.

The decrease in $J_{\mathrm{ph}}$ at lowering bias is due to two effects. First, undirected diffusion lowers the fraction of electrons (holes) that is collected at the $\mathrm{Al}$ anode (PEDOT cathode). ${ }^{14}$ Second, the increased transit time at lower bias leads, at constant $G_{0}$, to an increase in $n$ and $p$, and hence in $R$. To disentangle these effects, we repeated the calculation of the dashed curve with $R=0$ (dashed-dotted line). Actually, this calculation reproduces the analytical result of Sokel and Hughes. ${ }^{8,14}$ From the difference between the dashed and dashed-dotted line, it is evident that Langevin recombination is the dominant loss mechanism in the entire measured bias range.

From the above results, we conclude that the field dependence in the photocurrent can be adequately described by a constant generation rate and bimolecular recombination with dissimilar mobilities. We notice that for the used parameter sets, the modeled photocurrent is, at all shown biases, Downloaded 05 Feb 2007 to 131.155.151.20. Redistribution subje linear in the light intensity, in agreement with experimental observations. ${ }^{6,15}$ This finding indirectly refutes that bimolecular recombination always yields a nonlinear light intensity dependence. ${ }^{6,15}$

An alternative route to improve the correspondence is to assume the presence of a metastable bound CT state. ${ }^{8}$ In optical experiments in these solar cells, the presence of a CT state has been shown. ${ }^{2}$ However, its bound nature has not explicitly been demonstrated. After generation, such an electron-hole pair may either decay to the ground state with (constant) rate $k_{f}$, or dissociate with rate $k_{e}(E)$ into free carriers. This then leads to an explicit field dependence in the generation and recombination rate. In the presence of such a CT state the generation is described by a rate constant times the probability for the bound electron-hole pair to escape the attractive Coulomb force:

$$
\hat{G}(T, E)=G_{0} \frac{k_{e}(T, E)}{k_{e}(T, E)+k_{f}},
$$

where

$$
k_{e}(T, E)=k_{0}\left(1+b+\frac{b^{2}}{3}+\ldots\right),
$$

with

$$
b=\frac{e^{3} E}{8 \pi \varepsilon_{r} \varepsilon_{0} k_{B}^{2} T^{2}} .
$$

Here, $k_{0}$ is the zero-field rate constant. The expression between brackets follows from Onsager's theory ${ }^{16}$ commonly applied to describe the field and temperature dependence of photocurrent generation. ${ }^{13}$ In order to provide a consistent description, the bimolecular recombination must simultaneously be reduced to account for the possibility of reionization,

$$
\hat{R}(T, E)=R_{0} \frac{k_{f}}{k_{e}(T, E)+k_{f}},
$$

where $R_{0}$ is given by the bimolecular recombination previously described.

This description deviates from the numerical model used in Ref. 8 in the way the Onsager expression is incorporated to describe the field dependence of $G$ and $R$. The only additional free parameter in this implementation is the ratio $k_{f} / k_{0}$.

After optimizing $k_{f} / k_{0}$, with $\mu_{n}=2.0 \times 10^{-3}$ and $\mu_{p}$ $=1.4 \times 10^{-4} \mathrm{~cm}^{2} / \mathrm{V} \mathrm{s}$, the dotted curve is found. A much stronger field dependence in the photocurrent is found compared to that observed experimentally. Mihailetchi et al. ${ }^{8}$ showed that when a distribution of $k_{0}$, resulting from a spread in electron-hole separations in the CT state, is used, much better agreement with experiment is obtained. Actually, the increased slope in $J_{\text {ph }}$ prior to high-field saturation is reproduced by this means. In the field range studied here, in which only the onset of this feature is visible, the distribution in $k_{0}$ effectively switches off the field dependence of Eq. (3), ${ }^{17}$ and, hence, we can ignore the field dependence in the generation rate.

Several photocurrents are shown at different temperatures. By only altering the mobilities while retaining the same generation rate, good agreement is obtained at all temto AlP license or copyright, see http://apl.aip.org/apl/copyright.jsp 


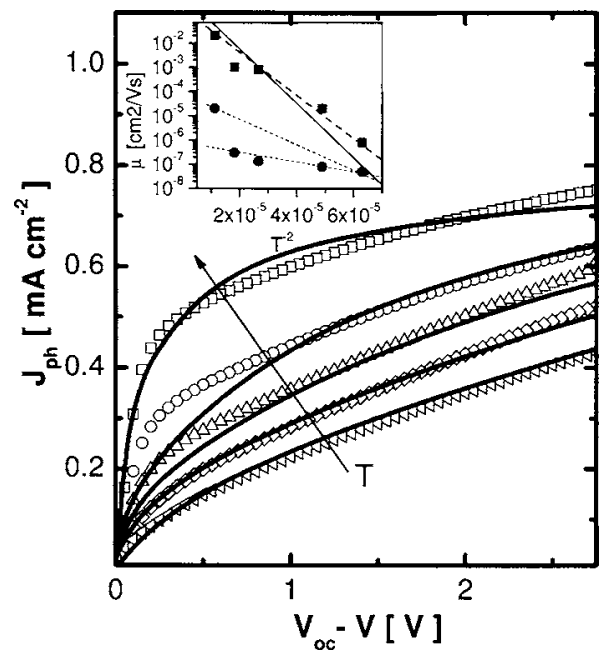

FIG. 2. The temperature dependence of the photocurrent vs bias. The solid curves are obtained by fitting the electron and hole mobility. $G_{0}$ was determined at $299 \mathrm{~K}$ and kept constant. $T=299,235,194,143$, and $126 \mathrm{~K}$ (top to bottom). Inset: Electron (squares) and hole (circles) mobilities used in the calculation vs $T^{2}$. Lines are fits to $\mu \exp \left[-\left(3 \sigma / 5 k_{B} T\right)^{2}\right]$. The solid line corresponds to $\sigma=0.073 \mathrm{eV}$.

peratures, see Fig. 2. At intermediate temperatures $(194-235 \mathrm{~K})$ and low bias $(<1 \mathrm{~V})$, deviation from experimental data is observed by at most $30 \%$.

The electron and hole mobilities that were used in these calculations are plotted versus $T^{2}$ in the inset of Fig. 2. Although the calculated photocurrent curves are not very sensitive to the used mobility values (typical uncertainties are a factor of 2 or 3 ), the broadening of the PCBM lowest unoccupied molecular orbital (LUMO) and PPV highest occupied molecular orbital (HOMO) levels can be estimated by fitting the used values with $\mu(E) \sim \exp \left[-\left(3 \sigma / 5 k_{\mathrm{B}} T\right)^{2}\right]{ }^{18}$ For PCBM, we find $\sigma_{\text {LUMO }} \approx 0.065 \mathrm{eV}$, in good agreement with the value of 0.073 reported in Ref. 18. For MDMO-PPV, we find $\sigma_{\mathrm{HOMO}}=0.03-0.05 \mathrm{eV}$. Despite the relatively large uncertainty, these values are clearly below the value of $0.11 \mathrm{eV}$ found for pure MDMO-PPV. This is consistent with the finding of Melzer et al. ${ }^{19}$ that the hole mobility in MDMO-PPV is enhanced upon blending with PCBM, since it is reasonable to expect that a reduced disorder results in an enhanced mobility. As an independent confirmation, we found that the mobilities reported here are entirely consistent with the (temperature dependent) impedance spectra taken on the same samples. $^{20}$
Finally, we note that within our modeling, the temperature dependence of $J_{\mathrm{ph}}$ in the entire bias range is explained by the temperature dependence of the carrier mobilities rather than the $T$ dependence of the generation rate. ${ }^{8}$

In summary, we demonstrate that the field and temperature dependence of photocurrents in bulk heterojunction organic solar cells can be explained in terms of the driftdiffusion equations by inclusion of bimolecular recombination. The modeling enables us to simultaneously estimate the broadening of the PCBM LUMO level and PPV HOMO level.

This research was supported by grants from the Dutch Foundation for Material Research (FOM). The authors gratefully acknowledge P. W. M. Blom for the stimulating discussions.

${ }^{1}$ C. J. Brabec, N. S. Sariciftci, and J. C. Hummelen, Adv. Funct. Mater. 11, 15 (2001); H. Hoppe and N. S. Sariciftci, J. Mater. Res. 19, 1924 (2004); K. M. Coakley and M. D. McGehee, Chem. Mater. 16, 4533 (2004).

${ }^{2}$ N. S. Sariciftci, L. Smilowitz, A. J. Heeger, and F. Wudl, Science 258, 1474 (1992).

${ }^{3}$ S. E. Shaheen, C. J. Brabec, N. S. Sariciftci, F. Padinger, T. Fromherz, and

J. C. Hummelen, Appl. Phys. Lett. 78, 841 (2001).

${ }^{4}$ C. J. Brabec, S. E. Shaheen, C. Winder, N. S. Sariciftci, and P. Denk, Appl. Phys. Lett. 80, 1288 (2002).

${ }^{5}$ P. Schilinsky, C. Waldauf, and C. J. Brabec, Appl. Phys. Lett. 81, 3885 (2002).

${ }^{6}$ I. Riedel, J. Parisi, V. Dyakonov, L. Lutsen, D. Vanderzande, and J. C. Hummelen, Adv. Funct. Mater. 14, 38 (2004).

${ }^{7}$ J. Nelson, Phys. Rev. B 67, 155209 (2003).

${ }^{8}$ V. D. Mihailetchi, L. J. A. Koster, J. C. Hummelen, and P. W. M. Blom, Phys. Rev. Lett. 93, 216601 (2004).

${ }^{9}$ J. A. Barker, C. M. Ramsdale, and N. C. Greenham, Phys. Rev. B 67, 075205 (2003)

${ }^{10}$ L. J. A. Koster, V. D. Mihailetchi, and P. W. M. Blom, Proc. SPIE 5520, 200 (2004)

${ }^{11}$ W. H. A. Schilders (unpublished).

${ }^{12}$ Langevin, Ann. Chim. Phys. 28, 433 (1903).

${ }^{13}$ M. Pope and C. E. Swenberg, Electronic Processes in Organic Crystals and Polymers, 2nd ed. (Oxford University Press, Oxford, 1999).

${ }^{14}$ R. Sokel and R. C. Hughes, J. Appl. Phys. 53, 7414 (1982).

${ }^{15}$ J. K. J. van Duren, X. Yang, J. Loos, C. W. T. Bulle-Lieuwma, A. B. Sieval, J. C. Hummelen, and R. A. J. Janssen, Adv. Funct. Mater. 14, 425 (2004).

${ }^{16}$ L. Onsager, J. Chem. Phys. 2, 599 (1934).

${ }^{17}$ L. J. A. Koster and P. W. M. Blom (private communication).

${ }^{18}$ V. D. Mihailetchi, J. K. J. van Duren, P. W. M. Blom, J. C. Hummelen, R. A. J. Janssen, J. M. Kroon, M. T. Rispens, W. J. Verhees, and M. M. Wienk, Adv. Funct. Mater. 13, 43 (2003).

${ }^{19}$ C. Melzer, E. J. Knoop, V. D. Mihailetchi, and P. W. M. Blom, Adv. Funct. Mater. 14, 865 (2004).

${ }^{20}$ H. H. P. Gommans, M. Kemerink, J. M. Kramer, and R. A. J. Janssen (unpublished). 